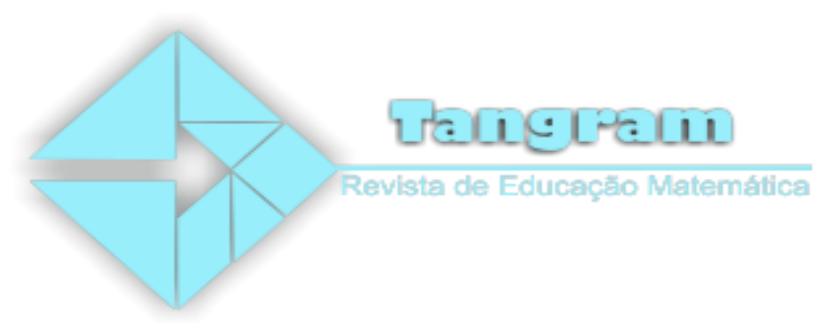

\title{
Aplicações das formas geométricas na escola da rede pública de ensino médio do município de Quixeramobim - CE
}

\author{
Applications of geometric shapes in the public high school in the \\ municipality of Quixeramobim - CE
}

Paulo Vitor da Silva Santiago ${ }^{1}$

Francisco Régis Vieira Alves ${ }^{2}$

\begin{abstract}
Resumo: A utilização de aplicações de formas geométricas para os adolescentes no processo de ensino. O presente trabalho tem como objetivo elucidar as aplicações das formas geométricas na disciplina de matemática no ensino médio. Inicialmente elenca-se as bases teóricas da geometria na matemática, suas funções e conceitos; relata-se formas geométricas como instrumento de aprendizagem; e por fim descreve-se o papel do educador no ensino de matemática em uma escola pública em tempo integral. A metodologia utilizada possui como base uma pesquisa bibliográfica com pesquisa em livros, revistas, periódicos, sites e pesquisa de campo, que relatam a importância do raciocínio lógico matemático. A problemática diz respeito a forma de utilização das formas geométricas como instrumento auxiliar pedagógico nas anos iniciais do ensino médio. A justificativa está pautada na disciplina de matemática como elemento fundamental para a percepção de teorias e práticas que vem sendo desenvolvidas e utilizadas no contexto da atualidade.
\end{abstract}

Palavras-Chave: Formas Geométricas. Matemática. Ensino.

Abstract: The use of geometric shape applications for adolescents in the teaching process. This paper aims to elucidate the applications of geometric shapes in the subject of mathematics in high school. Initially, it lists the theoretical bases of geometry in mathematics, its functions and concepts; it reports geometric forms as a learning tool; and finally, it describes the role of the educator in the teaching of mathematics in a full-time public school. The methodology used is based on a bibliographic research with research in books, journals, journals, websites and field research, which report the importance of mathematical logic reasoning. The problem concerns the use of geometric shapes as an auxiliary pedagogical tool in the early grades of high school. The justification is based on the discipline of mathematics as a fundamental element for the perception of theories and practices that have been developed and used in the current context.

\footnotetext{
${ }^{1}$ Mestrado Profissional em Ciências e Matemática pela UFC Atualmente é professor de Matemática - SEDUC Ceará, Brasil, pvitor60@hotmail.com.

${ }^{2}$ Doutorado com ênfase no ensino de Matemática (UFC ). Atualmente é professor do Centro Federal de Educação Tecnológica do Ceará / CE, Brasil, fregis@gmx.fr

Tangram - Revista de Educação Matemática, Dourados - MS - v.3 n.1, pp. 112-131 (2020)
} 


\section{Aplicações das formas geométricas na escola da rede pública de ensino médio do município de Quixeramobim - CE}

Keywords: Geometric. Mathematics. Teaching.

\section{Introdução}

A utilização das formas geométricas na disciplina de matemática é uma atividade que ajuda na condução do processo de ensino de forma concreta, favorecendo aos jovens a realização de um processo de adaptação aos cálculos aliados a realidade prática.

O presente trabalho possui como objetivo elucidar a aplicação das formas geométricas na disciplina de matemática na escola da rede pública de ensino médio do município de Quixeramobim, Estado do Ceará. O modo de aplicação de formas geométricas pode ser considerado uma atividade de conteúdo simbólico e concreto, onde os educandos facilmente conseguem resolver problemas até mesmo em um nível inconsciente.

Inicialmente, trata-se das bases teóricas das formas geométricas na matemática, suas funções e conceitos; relata-se das formas geométricas como instrumento de aprendizagem; e finalmente traça-se o papel do educador no ensino de matemática por intermédio da vertente em pauta.

O referido trabalho teve como suporte teórico os autores Sandra Lima de Vasconcelos Ramos (2014); Eduardo Sarquis Soares (2010) e Flávio Dias Ribeiro (2009). Tais referenciais contribuíram de forma positiva para reflexões propícias acerca dos enfoques matemáticos e suas implicações para o processo de ensino aprendizagem.

Os referidos autores contribuíram de forma positiva com reflexões significativas sobre como conduzir a atividade com significado, conscientes da necessidade de alcançar resultados satisfatórios nas aprendizagens de matemática.

A metodologia utilizada também possui como base uma pesquisa bibliográfica com ênfase em livros, revistas, periódicos, legislação pertinente ao assunto e sites que elucidam o caráter da importância das formas geométricas no raciocínio lógico matemático, e ainda, um estudo de caso.

A justificativa está pautada na disciplina de matemática como sendo um elemento fundamental para perceber como teorias e práticas foram sendo desenvolvidas e utilizadas em um contexto específico de cada época. Nesse sentido, buscar conhecer a historicidade e os pontos altos da matemática no passado poderá orientar no processo de aprendizado e no desenvolvimento dessa disciplina atualmente, para que não se repitam os erros do passado.

Tangram - Revista de Educação Matemática, Dourados - MS - v.3 n.1, pp. 112-131 (2020) 


\section{Aplicações das formas geométricas na escola da rede pública de ensino médio do município de Quixeramobim - CE}

É necessário propor um enfoque interligado a situações mais imediatas, e cotidianas, principalmente no que se refere ao utilitário, ao palpável, ao concreto e, sobretudo, ao desafio intelectual, ao raciocínio lógico para o intelecto de hoje.

\section{Referencial teórico}

A figura ou forma geométrica pode ser considerada como um conjunto, onde os componentes são pontos que enfatizam os fundamentos da geometria. A compreensão sobre a Geometria se remete ao estudo da disciplina que trata especificamente e detalhadamente das características principais, tais como: forma, extensão, propriedades e posição relativa.

Estudar as formas das figuras geométricas como o círculo, o triângulo, o quadrado, o retângulo, o pentágono, o trapézio e outros, ajuda a estimular o raciocínio lógico matemático, bem como, a memorização de cálculos simples e complexos, onde possam ser facilmente associados a situações-problemas.

A história da aplicação das formas geométricas faz parte de uma sólida construção humana que ultrapassa os limites do pensamento racional, pois envolve vários fatores tais como: sociais, econômicos, culturais, religiosos e de natureza intelectual. O trabalho, concebido como atividade humana é considerada como agente de transformação da natureza e do próprio meio em que se vive.

A aula de matemática representa uma importante contribuição no campo da educação com abordagem prática e metodológica no contexto educacional, portanto, é necessário compreender como ocorrem os pressupostos teóricos, metodológicos e pedagógicos de forma reflexiva sobre essa temática.

A função dos jogos na aprendizagem da geometria em sala de aula está interligada ao desencadeamento de um processo de resolução de desafios, problemas, visando à produção e ampliação de novos conhecimentos. Dessa forma, "o ambiente educativo deve ser entendido como um lugar de fascinação e inventividade, um lugar propício ao desenvolvimento da criatividade e da autonomia dos alunos" (Ribeiro, 2009, p. 22).

A geometria no cotidiano está presente em todos os lugares, tudo à nossa volta possui forma definida, portanto, é necessário utilizar exemplos práticos para que se possa entender o uso de tais formas geométricas. Isso implica na elaboração de enunciados que possam ser

Tangram - Revista de Educação Matemática, Dourados - MS - v.3 n.1, pp. 112-131 (2020) 


\title{
Aplicações das formas geométricas na escola da rede pública de ensino médio do município de Quixeramobim - CE
}

discutidos em sala de aula sobre a vida real dos educandos, ou seja, deve-se partir do princípio da funcionalidade do objeto de estudo.

\begin{abstract}
A Psicologia de desenvolvimento destaca que a brincadeira e o jogo desempenham funções psicossociais, afetivas e intelectuais básicas no processo de desenvolvimento. O jogo apresenta-se em uma atividade dinâmica que vem satisfazer uma necessidade da criança dentre outras, de "movimento", ação. (...) O jogo propicia um ambiente favorável ao interesse da criança não apenas pelos objetos que os constituem, mas também pelos desafios das regras impostas por uma situação imaginaria que, por sua vez, pode ser considerada como um meio ao desenvolvimento do pensamento abstrato (Ribeiro, 2009, p. 18).
\end{abstract}

As necessidades atingidas com jogos na geometria são eminentes no aspecto social, motor e intelectual, nesse aspecto, é, pertinente salientar que as regras são essenciais para a fixação dos conteúdos abordados e para a obtenção dos resultados positivos no processo avaliativo.

A relação das crianças ao jogar quanto à geometria está associada ao fato de que as formas são compreendidas com mais facilidade se estiverem em um contexto agradável, portanto, apenas o simples fato de observar a natureza, de brincar, de jogar, pode-se confirmar a existência, a presença de formas variadas tanto nos corpos materiais na natureza quanto nas invenções humanas, nesse sentido, forma-se a ideia de volume, de superfície, de linha e de ponto.

De acordo com os Parâmetros Curriculares Nacionais de Matemática - PCN (1997), “o ponto de partida da atividade matemática não é a definição, mas o problema”.

A definição da geometria em matemática pode ser facilmente compreendida na resolução de um problema, onde suas grandezas podem ser exploradas com fatos corriqueiros e os exemplos práticos são mais eficientes para a compreensão de enunciados e conceitos.

No processo de ensino e aprendizagem, conceitos, ideias e métodos matemáticos devem ser abordados mediante a exploração de problemas, ou seja, de situações em que os alunos precisem desenvolver algum tipo de estratégia para resolvê-las; a resolução de problemas não é uma atividade para ser desenvolvida em paralelo ou como aplicação da aprendizagem, mas uma orientação para a aprendizagem, pois proporciona o contexto em que se pode aprender conceitos, procedimentos e atitudes matemáticas (Ribeiro, 2009, p. 22). 


\section{Aplicações das formas geométricas na escola da rede pública de ensino médio do município de Quixeramobim - CE}

As estratégias podem influenciar no processo de ensino e aprendizagem tanto no contexto educacional, quanto ao longo da vida do ser humano. $\mathrm{O}$ ensino da geometria favorece a compreensão deste ao conceito de figuras geométricas fundamentais, tais como: o plano, o ponto e a reta, como também as mesmas formas e figuras como consequência de inúmeras transformações.

A história da geometria abrange aspectos pertinentes aos deslocamentos de seus componentes que podem produzir diferentes volumes, várias superfícies e/ou linhas, compreende-se que esse é o verdadeiro objeto de estudo da Geometria, aliada a topologia e, por conseguinte da matemática, dentre outras.

A respeito do ensino da geometria no ensino de matemática no Brasil, Ubiratan D’Ambrosio (1996), em seu livro intitulado: Educação matemática da teoria à prática relata a "adoção de uma nova postura educacional que substitua o já desgastado ensinoaprendizagem". O autor faz considerações de caráter geral e aborda aspectos relacionados à cognição, bem como a natureza da matemática, tratando de questões teóricas no campo da educação, discutindo as inovações na prática docente e ainda propondo reflexões sobre a matemática.

Nesse contexto, a história da geometria deve ser apresentada como importante para o processo de ensino e aprendizagem. Pode-se citar como exemplo: um pintor que utiliza os cálculos para saber a quantidade exata de tinta que será necessária para realizar a pintura de uma casa, partindo de sua experiência profissional.

A importância do lúdico na geometria possui respaldo na passagem do entendimento do abstrato ao concreto de forma agradável. Nesse sentido, as formas geométricas colaboram para enfatizarem o sentido da compreensão e resolução de cálculos com figuras de diversos tamanhos e formas.

O padrão da Escola Nova exigia certas características distintas tais como: "educação integral, intelectual, moral, física, educação ativa, prática, com obrigatoriedade de trabalhos manuais, exercício de autonomia, vida no campo, internato, co-educação, ensino individualizado".

Esse projeto exige métodos ativos, com mais ênfase nos processos de conhecimento do que propriamente no produto. Para tanto as atividades são centradas nos alunos, e a criação de laboratórios, oficinas, hortas ou até imprensa, conforme a linha a ser seguida, deve ter em vista a estimulação da iniciativa. Também se voltam para a compreensão da natureza 


\section{Aplicações das formas geométricas na escola da rede pública de ensino médio do município de Quixeramobim - CE}

psicológica da criança, o que orienta a busca de métodos para estimular o interesse sem cercear a espontaneidade (Aranha, 2006, p. 247).

A importância de laboratório de geometria se deve ao fato de que as aulas expositivas são na maioria das vezes cansativas e exaustivas. Uma aula de campo tende a fortalecer a busca por novos conhecimentos e aguçar a curiosidade dos alunos.

"Tentando superar o víeis intelectualista da escola tradicional, são valorizados os jogos, os exercícios físicos, as práticas de desenvolvimento da motricidade e da percepção, a fim de aperfeiçoar as mais diversas habilidades" (Aranha, 2006, p. 247).

São estratégias viáveis para o desenvolvimento mental, social, com ênfase no desenvolvimento da linguagem (visual, corporal, gestual, oral ou escrita), que podem contribuir de maneira singular, na medida em que cada criança interage de forma única e significativa, proporcionando as crianças desafios que promovem a aprendizagem de forma lúdica.

Pode-se ter como base para isso uma prática pedagógica inspirada nos princípios Vygotskyanos que toma como ponto de partida a realidade dos alunos. A inspiração é um atributo especial que deve fazer parte das qualidades do professor como mediador do processo de ensino e aprendizagem, para que possa repassar para os alunos sem maiores dificuldades tudo que aprendeu. Os problemas da geometria favorecem a baixa autoestima do aluno.

Nesse aspecto, compreende-se o jogo como uma atividade de resolução de problemas, ele é uma charada que desencadeia a edificação de novos conceitos ou ideias geométricas, de forma motivadora e desafiadora. Ao se desenvolver uma tarefa voltada á solução de um problema, espera-se conduzir à compreensão de um fato geométrico.

Naturalmente, para a concretização dessa ideia, é necessário um estudo minucioso do jogo que se pretende propor aos alunos, bem como das estratégias que serão adotadas. Esse fator é considerado fundamental para que o uso do jogo não se reduza a uma mera atividade desconectada do processo de ensino-aprendizagem, caracterizada como um apêndice em sala de aula ou mesmo o resultado de um modismo (Ribeiro, 2009, p. 22).

Para que a geometria na matemática se torne uma matéria preferida, o professor necessita de um método eficaz, ainda que seja pouco utilizado em sala, quando é utilizado 


\section{Aplicações das formas geométricas na escola da rede pública de ensino médio do município de Quixeramobim - CE}

um material e/ou metodologia adequada para cada nível de aprendizagem de cada aluno existe uma ferramenta poderosa, chamada jogo matemático.

As escolas brasileiras são recordistas em atividades lúdicas, mas pouco se tem dado o devido valor a esse fato, poucas publicações remontam o papel fundamental do educador na condução de jogos.

A prática pedagógica é um componente bastante importante no processo de ensinoaprendizagem, a mesma possibilita ao professor, uma diversidade de instrumentos pedagógicos, que podem ser trabalhados no cotidiano escolar de acordo com a realidade de cada aluno, tendo em vista que um método utilizado em uma sala de aula de forma perfeita não é sinônimo de que esse mesmo método irá funcionar da mesma maneira com alunos de outra sala de aula.

Existem instrumentos pedagógicos que nos possibilitam de várias maneiras atrair a atenção do educando em nossas aulas, através, por exemplo, de aulas dinâmicas (aulas práticas), utilização de meios tecnológicos do tipo: Computadores, data show, tablet e até mesmo o próprio celular dos alunos, desde que utilizado para fins pedagógicos, estes equipamentos por sua vez podem auxiliar aos mesmos em pesquisas para a resolução de trabalhos e elaboração de seminários.

Quando se lida com a disciplina de matemática, temos que estar preparados para vários obstáculos que nos vem à frente, pois é uma das disciplinas mais odiadas, mas quando os alunos conhecem a sua aplicabilidade se torna uma das mais amadas.

Ensinar geometria é desenvolver o raciocínio lógico, estimular o pensamento independente, a criatividade e a capacidade de resolver problemas. Enquanto, educadores devem procurar alternativas para aumentar a motivação da aprendizagem, desenvolver a autoconfiança, a organização, a concentração, a atenção, o raciocínio lógico-dedutivo e o senso cooperativo, estimulando a socialização e aumentando as interações do indivíduo com outras pessoas.

É interessante observar que as vantagens apontadas pela autora estão intimamente voltadas ao desenvolvimento da criatividade e da autonomia dos alunos, o que leva a afirmar que um trabalho sério como uso de jogos nas aulas de matemática pode ser um grande incentivo a promoção dessas características (Ribeiro, 2009, p. 23). 


\section{Aplicações das formas geométricas na escola da rede pública de ensino médio do município de Quixeramobim - CE}

A observação do comportamento de uma criança é válida para avaliar suas atitudes, e em diversas situações, pode encontrar e reestruturar novas relações, e dessa forma, resolver problemas.

Para se trabalhar com jogos, deve-se ter uma aula amplamente planejada, sendo assim será um recurso pedagógico eficaz para a construção do conhecimento matemático. O uso de jogos no ensino da Matemática tem o objetivo de fazer com que os estudantes gostem de aprender essa disciplina, mudando a rotina da classe e despertando o interesse do estudante.

Neste sentido, verifica-se que há três aspectos que por si só justificam a incorporação do jogo nas aulas. São estes: o caráter lúdico, o desenvolvimento de técnicas intelectuais e a formação de relações sociais (Moura, 1991).

Os jogos podem ser utilizados para introduzir, amadurecer conteúdos e preparar o estudante para aprofundar os itens já trabalhados. Devem ser escolhidos e preparados com cuidado para levar o estudante a adquirir conceitos matemáticos de importância.

\footnotetext{
Outro motivo para a introdução de jogos nas aulas de matemática é a possibilidade de diminuir bloqueios apresentados por muitos de nossos estudantes que temem a Matemática e sentem-se incapacitados para aprendê-la. Dentro da situação de jogo, onde é impossível uma atitude passiva e a motivação é grande, notamos que, ao mesmo tempo em que estes alunos falam Matemática, apresentam também um melhor desempenho e atitudes mais positivas frente a seus processos de aprendizagem (Borin, 1996, p. 16).
}

Deve escolher jogos que estimulem a resolução de problemas, principalmente quando o conteúdo a ser estudado for abstrato, difícil e desvinculado da prática diária, sem esquecerse de respeitar as condições de cada comunidade e o querer de cada aluno. Essas atividades não devem ser muito fáceis nem muito difíceis e ser testadas antes de sua aplicação, a fim de enriquecer as experiências através de propostas de novas atividades, propiciando mais de uma situação.

Segundo Malba Tahan (1968), "para que os jogos produzam os efeitos desejados é preciso que sejam de certa forma, dirigidos pelos educadores". Partindo do princípio que as crianças pensam de maneira diferente dos adultos e de que nosso objetivo não é ensiná-las a jogar, deve-se acompanhar a maneira como as crianças jogam, sendo observadores atentos, interferindo para colocar questões interessantes (sem perturbar a dinâmica dos grupos) para, a partir disso, auxiliá-las a construir regras e a pensar de modo que elas entendam.

Tangram - Revista de Educação Matemática, Dourados - MS - v.3 n.1, pp. 112-131 (2020) 


\section{Aplicações das formas geométricas na escola da rede pública de ensino médio do município de Quixeramobim - CE}

Nesse sentido, destaca-se a importância da eficácia da metodologia de resolução de problema, sendo considerada como uma nova abordagem que confere significado diferenciado ao conhecimento em geometria.

No ensino de matemática, já existe muitas possibilidades de trabalhar os conceitos desta disciplina, não utilizando o ensino tradicional, mas, levando em consideração outras propostas metodológicas, como a resolução de problemas, a abordagem Etnomatemática, o uso de computadores, a modelagem geométrica, procurando fazer com que o aluno deixe de ser um simples receptor de conteúdos, passando a interagir e participando do próprio processo de construção do conhecimento.

A matemática é bastante valorizada. Está presente em todos os currículos do ensino fundamental e do ensino médio, nos exames de admissão a universidades, naqueles de admissão a empregos. É tida como disciplina básica na escola e como conhecimento indispensável para a realização de várias atividades próprias dos sistemas produtivos (Soares, 2010, p. 7).

O cognitivo, o emocional não difere muito dos demais aspectos sócios afetivos que compõem o desenvolvimento do ser humano, portanto, a criança é carente de estímulos positivos e de situações práticas desafiadoras para que ocorra a aprendizagem significativa.

Os jogos, ultimamente, vêm ganhando espaço em nossas escolas numa tentativa de trazer o lúdico para dentro da sala de aula. A pretensão da maioria dos professores, com a sua utilização, é a de tornar as aulas mais agradáveis com o intuito de fazer com que a aprendizagem se torne algo fascinante.

As atividades lúdicas podem ser consideradas como uma estratégia que estimula o raciocínio levando o aluno a enfrentar situações conflitantes relacionadas com seu cotidiano e, também, a utilização dos jogos vem confirmar o valor formativo da matemática, não no sentido apenas de auxiliar na estruturação do pensamento e do raciocínio dedutivo, mas, também, de auxiliar na aquisição de atitudes.

Logo brincando e jogando a criança pode exercitar processos mentais significativos para o desenvolvimento da linguagem e de hábitos sociais. No contexto das aprendizagens escolares, embora apresente grande atividade motora e crescente energia, a partir dos três anos de idade a criança já é capaz de dedicar parte de seu tempo a realização de jogos sedentários (Ramos, 2014, p. 19).

Tangram - Revista de Educação Matemática, Dourados - MS - v.3 n.1, pp. 112-131 (2020) 


\section{Aplicações das formas geométricas na escola da rede pública de ensino médio do município de Quixeramobim - CE}

Uma vez que o professor planeja a exploração do jogo, este deixa de ser desinteressante para o aluno, porque visa à elaboração de processos de análise de possibilidades e tomada de decisão: habilidades necessárias para o trabalho com a resolução de problemas, tanto no âmbito escolar como no contexto social no qual estão inseridos.

Para essa elaboração, o aluno é forçado a criar processos pessoais para que possa jogar e resolver os problemas que inesperadamente irão surgir, elaborando assim novos pensamentos e conhecimentos, deixando de seguir sempre a mesma receita.

Para Furlanetto (2013, p. 3), "quando os professores utilizam materiais manipuláveis, devem ter clareza quanto aos objetos matemáticos que pretendem desenvolver, por meio de um planejamento adequado".

Hipoteticamente, acredita-se que os professores até tentam usar novos instrumentos pedagógicos tecnológicos como aqueles já citados anteriormente, porém não se consegue ter uma sequência boa durante todo o ano, pois o principal motivo de não usarem com mais frequência é de que existem muitos professores da escola que também desejam usufruir destes novos meios tecnológicos, todavia essa prática fica impedida de ser desenvolvida por todos porque não existem equipamentos suficientes para atender toda a demanda.

A organização da sala de aula e o aproveitamento do tempo com dinâmicas e ludicidade conduzem uma educação favorável e propicia a novas descobertas, a abertura de ampliação de novos conhecimentos, pelas quais os educandos têm acesso ao material concreto e ao sucesso educacional.

A aula de geometria representa uma importante contribuição no campo da educação com abordagem prática e metodológica no contexto educacional, portanto, é necessário compreender como ocorrem os pressupostos teóricos, metodológicos e pedagógicos de forma reflexiva sobre essa temática.

As oficinas de construção de jogos são essenciais para o desenvolvimento das crianças, bem como para o processo de aprendizagem propriamente dito. Quando a criança tem acesso ao material de produção e confecção de brinquedos e jogos, ocorre uma facilidade na construção do conhecimento e entendimento de situações problemas que dificilmente seriam resolvidas apenas com a leitura de um enunciado.

Independentemente da idade deve-se ter um olhar do profissional na educação, sensível e comprometido, e além de tudo, preocupado com o ensino que contribua para uma aprendizagem significativa.

Tangram - Revista de Educação Matemática, Dourados - MS - v.3 n.1, pp. 112-131 (2020) 


\section{Aplicações das formas geométricas na escola da rede pública de ensino médio do município de Quixeramobim - CE}

Nesse sentido, ao analisar as práticas pedagógicas de professores utilizadas na sala de aula das escolas públicas e privadas, busca-se compreender a dinâmica utilizada e a linguagem especifica, e ainda em um contexto mais específico verificar o conhecimento dos professores acerca de instrumentos de ensino e debater a importância de se aplicar diferentes metodologias de acordo com a realidade de cada sala de aula.

Acredita-se que é de extrema importância a escolha adequada de práticas pedagógicas que serão utilizadas dentro das aulas de geometria, principalmente aquelas relacionadas à motricidade e a socialização para assim melhorar o processo de ensino e aprendizagem.

\section{Metodologia}

Será realizado através de uma pesquisa de campo do tipo qualitativa, definida da seguinte forma: aquela utilizada com o objetivo de conseguir informações e/ou conhecimentos acerca de um problema, para o qual se procura uma resposta, ou de uma hipótese, que se queira comprovar ou descobrir novos fenômenos ou as relações entre eles. A mesma é qualitativa por buscar o ambiente natural como sua fonte direta de dados, na qual os investigadores se preocupam essencialmente com o significado que as pessoas dão aos acontecimentos.

A pesquisa exploratória realizada diz respeito à pesquisa quase cientifica ou não cientifica que não requer a elaboração de hipóteses a serem testados no trabalho, restringindo-se a definir objetivos e buscar mais informações sobre determinado assunto de estudo.

Nesse sentido, busca-se compreender por meio de entrevistas a forma de ensinar geometria no ensino médio, mais especificamente na disciplina de matemática, no sentido de obter uma melhor familiarização com o fenômeno como também obter uma nova percepção, para finalmente descobrir novas ideias.

A instituição escolhida para a pesquisa foi a EEEP Dr. José Alves da Silveira de Quixeramobim, pertencente à rede estadual e situada na Zona Urbana do Município de Quixeramobim - CE, mais precisamente no centro da cidade, na qual funciona o Ensino Médio nos dois turnos.

Fundada em 17 de maio de 2011, iniciando suas atividades no dia 19 de maio de 2011, ofertando cursos na área técnica em Agronegócios, Edificações, Logística e Redes de Tangram - Revista de Educação Matemática, Dourados - MS - v.3 n.1, pp. 112-131 (2020) 


\section{Aplicações das formas geométricas na escola da rede pública de ensino médio do município de Quixeramobim - CE}

Computadores. Em 2012, após seleção para os cursos técnicos em Agrimensura, Edificações, Nutrição e Dietética e Redes de Computadores, o quadro de alunos da Instituição praticamente duplicou, passando a contar com mais de 350 estudantes. Com a entrada de novos alunos, o quadro de educadores passou a contar com 22 profissionais.

Como instrumentos de coleta de dados serão aplicados questionários semiestruturados contendo 08 questões cada, onde o público alvo irá responder, o mesmo será desenvolvido para responder de forma mais direta possível os objetivos relacionados ao trabalho. Será utilizado como método de análise o dialético, já que ele visa à interpretação dinâmica e totalizante da realidade.

Esse questionário, será analisado no sentido de se obter as percepções dos professores, em relação aos aspectos que dizem respeito ao desenvolvimento cognitivo, como raciocínio lógicos, dedução, desenho, formas geométricas, afetivos dos alunos nos mais diversos contextos, a fim de realizar as maiores dificuldades encontradas por eles e pelos próprios professores em relação ao ensino e aprendizado da matemática.

Os alunos serão submetidos a testes de diagnósticos com atividades envolvendo formas geométricas, raciocínio lógico matemático e resolução de problemas de cálculos com geometria.

A fim de analisar os problemas evidenciados pela matemática foram entrevistados os professores de Matemática da referida escola, Everton Sousa, licenciado pela UECE Universidade Estadual do Ceará em Matemática e Mestre em Matemática pela UFC Universidade Federal do Ceará, seguido pelo professor Júlio Cesar licenciado em Matemática pelo IFCE - Instituto Federal do Ceará.

O instrumento foi aplicado no período de agosto a setembro de 2016 para 45 alunos da $2^{\mathrm{a}}$ série do Ensino Médio, com faixa etária entre 14 e 16 anos de idade com uma situação socioeconômica média. Devido à grande quantidade de alunos residirem no bairro, grande parte dos alunos vão a pé para a escola, uma pequena parcela utiliza outros meios como bicicleta, carro, moto e transporte coletivo. Muitos residem em casa própria com os pais, também há um número significativo que mora apenas com a mãe e uma parcela menor com os avós. Há ainda, alguns que residem só com o pai ou com outros familiares. A renda familiar é em média de três salários mínimos. Há uma pequena parcela que a renda familiar é de mais de cinco salários mínimos. A maior parte dos alunos pertence à religião católica.

Tangram - Revista de Educação Matemática, Dourados - MS - v.3 n.1, pp. 112-131 (2020) 


\section{Aplicações das formas geométricas na escola da rede pública de ensino médio do município de Quixeramobim - CE}

Dificuldade encontrada em alguns alunos é a interpretação de textos matemáticos, resoluções de exercícios, e aplicação de ângulos em desenho. O método de investigação para realizar o diagnostico situacional da Escola Municipal foi o de questionário estruturado. Este consistiu em aplicar aos professores da área de ensino de Matemática e alunos da $2^{\mathrm{a}}$ série do Ensino Médio que estuda em turno integral.

A aplicação dos jogos foi de forma coletiva para os alunos, sendo que uma equipe se utilizou de uma pesquisa externa a escola e outras ajuda dos professores. Para os outros sujeitos de pesquisa o preenchimento do questionário foi feito de forma individual.

Pode-se concluir que a diversidade de materiais para uma boa aula de geometria pode e deve ser utilizada por todos os professores como forma de interdisciplinaridade, ou seja, os jogos e o material lúdico, bem como as aulas práticas e de campo são importantes em todas as disciplinas e favorecem o aprendizado no aluno enquanto agente de transformação.

As aulas com formas geométricas na área da matemática quando bem ministradas e conduzidas traduzem um novo significado ao educando, pois propiciam uma melhor concentração e desenvolve habilidades que são necessários ao longo da vida do ser humano, tanto no quociente intelectual (inteligência) como no quociente emocional (sentimentos).

Nesse aspecto, o aluno aprende na prática o sentido de ganhar e perder como um processo normal que faz parte da vida e do aprendizado é uma preparação para a vida adulta, para o ingresso no mercado de trabalho cada vez mais competitivo e acirrado.

Espera-se que o resultado seja positivo com um considerável avanço na aprendizagem, compreensão e assimilação de novos conhecimentos.

\section{Análise dos dados}

Questionados sobre quais metodologias de trabalho com matemática os professores utilizavam, tem-se que, em uma escala de 0 a 100\%, o resultado é: $30 \%$ utilizam recursos multimeios, tais como a sala de informática e os notebooks; $10 \%$ utiliza aula expositiva, livro e caderno de atividades (aula tradicional); $38 \%$ utiliza jogos matemáticos e de raciocínio lógico; $2 \%$ utiliza materiais paradidáticos; $10 \%$ utiliza materiais lúdicos e aula de campo (teoria e prática); $10 \%$ utiliza todos os recursos disponíveis na escola como o data show, o laboratório de informática, a biblioteca, jogos de xadrez, dama, campo minado, sudoku, material dourado, trilha, quebra cabeças, trilha e outros.

Tangram - Revista de Educação Matemática, Dourados - MS - v.3 n.1, pp. 112-131 (2020) 


\section{Aplicações das formas geométricas na escola da rede pública de ensino médio do município de Quixeramobim - CE}

Segundo os professores entrevistados, a utilização dos jogos na escola como estratégia de ação no sentido de favorecer a facilidade de assimilação dos conhecimentos em matemática não é algo novo, assim como é bastante conhecido o seu potencial para o ensino e a aprendizagem em muitas áreas do conhecimento.

\section{Resultados}

O resultado específico de cada aluno, foi feito pela sua complexidade de percepção, uma vez que ele é adquirido de uma forma diferenciada que foge dos padrões convencionais de aprendizagem, gerando a diversificação dos sentidos de compreensão. As atividades aconteceram e um dinamismo utilizado com todas as equipes, divididas em nove no total, para uma melhoria do cotidiano corriqueiro da sala de aula.

Na primeira parte do questionário constaram perguntas sobre a formação acadêmica de cada um deles, como se pode observar abaixo:

Quadro 1 - Formação acadêmica dos professores

\begin{tabular}{|c|c|c|c|c|}
\hline Formação Acadêmica & $\begin{array}{c}\text { Tempo } \\
\text { Formado }\end{array}$ & Especialização & $\begin{array}{c}\text { Outro curso de } \\
\text { Pós-Graduação }\end{array}$ \\
\hline P2 & Matemática & 25 anos & $\begin{array}{c}\text { Ensino da } \\
\text { Matemática }\end{array}$ & $\begin{array}{c}\text { Mestrado em } \\
\text { Matemática }\end{array}$ \\
\hline
\end{tabular}

Fonte: Autores, 2016.

Percebe-se que dos dois professores entrevistados apenas um possui formação em nível de Mestrado na área de Matemática. Este último, além de professor de matemática, ele atua com jogos matemáticos fora da escola.

O primeiro jogo apresentado é o cubo mágico, onde desperta a curiosidade do aluno e pode ajudar o professor a atrair parte dessa curiosidade para a matemática, associando o cubo ao professor, e possibilita o raciocínio lógico do aluno para alguns problemas da matemática.

O xadrez vem dar suporte, como a $2^{\circ}$ ferramenta utilizada, na qual foi trabalhado que o xadrez é um tabuleiro que evidência a questão de 8x8 locais, ou seja, há oito colunas e oito linhas. Pode contar quantas casas há no total elevando o número 8 ao quadrado, ou em termos

Tangram - Revista de Educação Matemática, Dourados - MS - v.3 n.1, pp. 112-131 (2020) 


\section{Aplicações das formas geométricas na escola da rede pública de ensino médio do município de Quixeramobim - CE}

matemáticos, $8^{2}=64$. São 30 diagonais, se contar nos dois sentidos, sendo 2 inteiras e 28 parciais, e entre essas 4 possuem apenas 1 casa, justamente os 4 cantos. São 32 casas que pertencem ao domínio de cada um dos 2 conjuntos de 16 peças que representam as equipes. Outra análise matemática pode ser feita no número de casas que cada peça pode percorrer: um peão anda no máximo 7 casas; um bispo 32 casas; o cavalo, a torre, a rainha e o rei podem percorrer o tabuleiro inteiro, ou seja, as 64 casas. O cavalo tem mais uma curiosidade: em cada movimento ele pode escolher até 8 casas (dependendo da sua localização), que é justamente a raiz quadrada do total de casas possíveis que ele pode percorrer.

Em relação ao tempo de atuação no ensino de Matemática e, especificamente, desta disciplina da $2^{\mathrm{a}}$ série, obtivemos as seguintes informações:

\begin{tabular}{|c|c|c|}
\hline \multicolumn{3}{|c|}{ Quadro 2-Tempo de ensino } \\
\hline P1 & Tempo de ensino na Matemática & $\begin{array}{c}\text { Tempo de ensino na } \\
\text { matemática da 2a série }\end{array}$ \\
\hline P2 & Seis anos e seis meses & Quatro anos \\
\hline
\end{tabular}

Fonte: Autores, 2016.

Os professores pesquisados atuam no ensino de matemática há mais de seis anos por terem um tempo de contribuição em outras escolas.

Ao questionar os professores sobre sua vivência com a Geometria durante sua trajetória acadêmica, percebe-se que a minoria teve o aprofundamento necessário nessa área da matemática.

Em conversa com o professor P1, ele afirma que procurou fazer aulas particulares quando já atuava em sala de aula, para que adaptasse à escola integral, pois, segundo ele, não possui muita afinidade com essa área.

Gráfico 1. Opinião dos professores sobre tempo de ensino.

Tangram - Revista de Educação Matemática, Dourados - MS - v.3 n.1, pp. 112-131 (2020) 


\section{Aplicações das formas geométricas na escola da rede pública de ensino médio do município de Quixeramobim - CE}

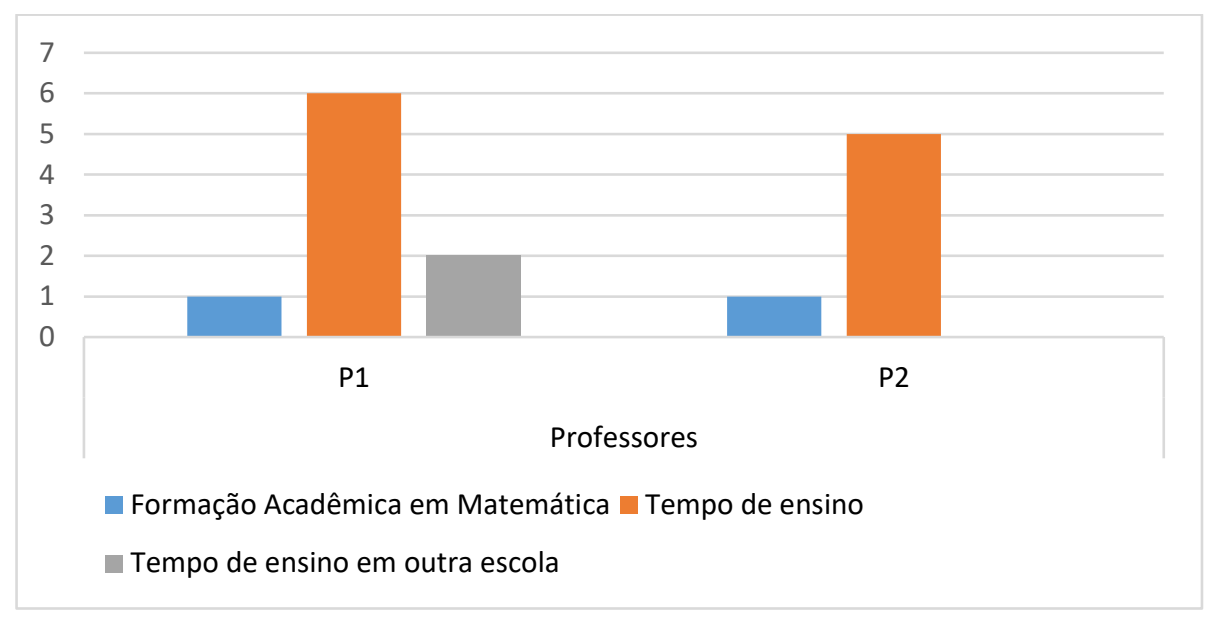

Fonte: Pesquisa direta realizada na Escola Municipal de Tempo Integral-CE em 2016.

A resolução dos problemas foi escolhida pelos dois professores para atribuir uma nota para a disciplina de Matemática como média parcial da avaliação semestral. Avaliar a prática de desenho geométrico, ângulos e a interpretação de questões voltadas para situações reais do cotidiano vivenciado em sala de aula.

A resolução de problemas é trabalhada com os alunos de acordo com cada resolução, o professor percorre as carteiras ajudando, encorajando, dando ideias, pequenas "dicas" (sem contar como se chega à solução), deixando claro quais são os objetivos, os dados do problema, as condições etc. O professor pode também, ele mesmo, ir registrando no quadro as sugestões dos alunos. É comum aparecerem maneiras diferentes de resolver o mesmo problema, inclusive algumas erradas, e é interessante que todas sejam discutidas e analisadas, pois isso incentiva os alunos a sempre tentarem vários métodos. Deve-se observar que um problema não está necessariamente resolvido quando o aluno encontrou a resposta certa. Para estar necessariamente resolvido, o aluno precisa saber o que e como fez, e por que sua ação foi apropriada. E isso deve ser parte integrante da resolução do problema, na etapa de revisão da solução.

O material utilizado foi o livro didático no qual os professores utilizam na sala de aula e em seus planejamentos, apenas o professor P2 admite utilizar jogos matemáticos e outros meios tecnológicos, como exemplos foram citados o computador e calculadora cientifica (esta é utilizada apenas com a turma da $2^{\mathrm{a}}$ e $3^{\mathrm{a}}$ do ensino médio) e o professor P1 respondeu que utiliza o compasso, régua, esquadros e jogos para repassar os conteúdos em suas aulas.

Foi realizada uma pesquisa de campo do tipo qualitativa como forma de se utilizar como objetivo de conseguir informações acerca de problemas relacionados a Geometria. $\mathrm{Na}$ Tangram - Revista de Educação Matemática, Dourados - MS - v.3 n.1, pp. 112-131 (2020) 


\section{Aplicações das formas geométricas na escola da rede pública de ensino médio do município de Quixeramobim - CE}

entrevista realizada com alunos da $2^{\text {a }}$ série do Ensino Médio de uma Escola Municipal de Tempo Integral voltada a definição de formas geométricas em representação de desenhos e problemas situações reais, para uma familiarização de assuntos vistos rápidos por eles e pelo professor. No questionário foi analisado o sentido de se obter as percepções por partes dos dois professores em relação aos aspectos do desenvolvimento cognitivo, como raciocínio lógico, dedução, desenho, formas geométricas, entre outros, e afetivos dos alunos nos mais diversos contextos, a fim de realizar as maiores dificuldades encontradas por eles e pelos próprios professores em relação ao ensino e aprendizado da matemática.

Os estudos para a história inicial da geometria abordaram situações relacionadas à forma, dimensão e semelhança. $\mathrm{O}$ objetivo de ensinar geometria aos da $2^{\mathrm{a}}$ série está ligado ao sentido de localização, desenhos, reconhecimento de figuras, manipulação de formas geométricas, representação e estabelecer as propriedades.

Foi feito uma leitura detalhadamente do contexto da história da matemática da geometria plana, depois partimos para uma aplicação de questões resoluções no quadro branco, evolvendo todos na participação e tira dúvidas, os professores sentiram motivados por ter um melhor retorno e acompanhamento, os alunos alguns tinham dificuldades em uma ou duas questões.

A aplicação da avaliação foi realizada na percepção geométrica, onde os alunos serão capazes de visualizar diferentes figuras geométricas, planas e espaciais realizando a classificação e discriminação por meio de suas características e atributos.

A aplicação da prova foi bastante razoável com dez questões de geometria plana e espacial, conteúdo duas questões abertas e oito fechadas, sendo alternadas em relação à elaboração de questões com difíceis medias e quatro difíceis.

Tangram - Revista de Educação Matemática, Dourados - MS - v.3 n.1, pp. 112-131 (2020) 


\section{Aplicações das formas geométricas na escola da rede pública de ensino médio do município de Quixeramobim - CE}

Gráfico 2. Referente à nota parcial dos alunos da $2^{\mathrm{a}}$ série do Ensino Médio.

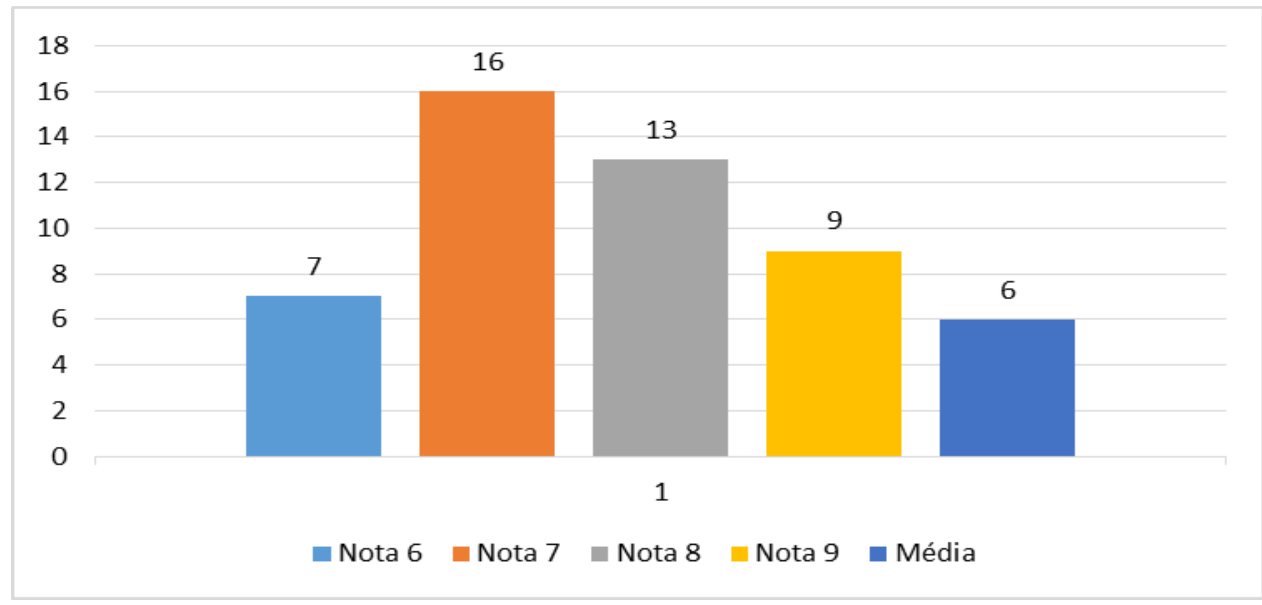

Fonte: Avaliação de Matemática realizada na Escola Municipal de Tempo Integral-CE em 2016.

Evolução dos alunos se desenvolve no sentido da lógica em seu cérebro e raciocínio, e isso serve para sua vida inteira, vale ressaltar que alguns alunos se sobre saíram muito bem nas questões difíceis. Anote-se que o acompanhamento foi proveitoso de acordo com cada professor com êxito de gratidão e missão cumprida relacionado ao aprendizado de cada aluno.

Os pontos negativos em destaque foram o tempo que cada professor dispõe em sala de aula para realização das atividades. Uma vez que o professor trabalhando com um modelo ele gasta muito mais tempo do que dispõe para aplicação da avaliação. O excesso no número de aluno, acaba não dando condições para que o professor execute a modelagem de forma positiva, pois é no momento da construção do modelo de exercícios que o aluno passa a ver vários pontos interessantes, até então o momento que o professor estar abrangendo a possibilidade de interação entre vários conteúdos voltados para a geometria.

A possibilidade real do aprendizado da matemática e da sua aplicação, a partir da interação com a realidade, o aluno como pesquisador e disposto a argumentar sobre os exercícios. A interação entre o professor e aluno é ótima, por todos eles se adaptarem a metodologia de aplicação e resolução de problemas, destaca-se também que a avaliação foi um ponto positivo mais visto pelos professores da área por atribuir a história, conceito, aplicação e avaliação.

Tangram - Revista de Educação Matemática, Dourados - MS - v.3 n.1, pp. 112-131 (2020) 


\section{Aplicações das formas geométricas na escola da rede pública de ensino médio do município de Quixeramobim - CE}

\section{Considerações finais}

Pode-se concluir que a diversidade de materiais para uma boa aula de matemática pode e deve ser utilizada por todos os professores como forma de interdisciplinaridade, ou seja, os jogos e o material lúdico, bem como as aulas práticas e de campo são importantes em todas as disciplinas e favorecem o aprendizado no aluno enquanto agente de transformação.

As aulas de matemática quando bem ministradas e conduzidas traduzem um novo significado ao educando, pois propiciam uma melhor concentração e desenvolve habilidades que são necessários ao longo da vida do ser humano, tanto no quociente intelectual (inteligência) como no quociente emocional (sentimentos).

Nesse aspecto, o aluno aprende na prática o sentido de ganhar e perder como um processo normal que faz parte da vida e do aprendizado, é uma preparação para a vida adulta, para o ingresso ao mercado de trabalho cada vez mais competitivo e acirrado.

Os professores valorizam os jogos e a ludicidade porque consideram importante destacar que as atividades lúdicas são inerentes ao ser humano, desde a antiguidade até a atualidade, não somente no universo infantil, mas também nas vivencias dos adultos. Quantas vezes nos surpreendemos realizando algum tipo de atividade lúdica, como sair cantarolando, brincar de "em que mão está?" ou, de modo mais sistematizado, em atividades de jogos com regras, como jogo de boliche, cartas, dominó etc.

Nesse sentido, o conceito do jogo no contexto pedagógico dos professores estudados deve ir além do apenas jogar; ele deve ganhar destaque para apoiar os alunos em suas dificuldades, fazendo com que os conteúdos matemáticos saiam da sua abstração e tenham um significado concreto na visão dos alunos.

A utilização de jogos em sala de aula pode contribuir de forma positiva para o aprendizado dos alunos, uma vez que as atividades podem ser associadas e adaptadas à realidade, como uma forma de vivência lúdica. Nesse sentido, uma simples atividade de conteúdo estritamente simbólico é utilizada para resolver os mais diversos problemas, em um nível inconsciente.

No universo atual dos alunos, tantos os jogos como as mais simples brincadeiras ocupam um lugar todo especial. Nesse aspecto, é necessário canalizar as energias para que os jogos sejam direcionados ao processo de aprendizagem, como ferramenta que auxilia na assimilação de conteúdos, internalização de conceitos e apreensão de novos conhecimentos. Tangram - Revista de Educação Matemática, Dourados - MS - v.3 n.1, pp. 112-131 (2020) 


\section{Aplicações das formas geométricas na escola da rede pública de ensino médio do município de Quixeramobim - CE}

Para os professores, os alunos jogam porque o jogo, em si mesmo, é um prazer, porém a maior importância reside no fato de que permite resolver simbolicamente os problemas e possibilita pôr em prática distintos processos mentais.

\section{Referências}

Aranha, M. L. A.(2006) História da educação e da pedagogia: geral e Brasil. $3^{\mathrm{a}}$ ed. São Paulo: Moderna..

Borin, J.(1996) Jogos e Resolução de Problemas: Uma estratégia para as aulas de matemática. $2^{\mathrm{a}}$ ed. São Paulo: IME-SP.

Brasil. (1997)Parâmetros Curriculares Nacionais. Brasília: MEC/SEF.

D’ambrosio, U. (1996) 1932 - Educação matemática: Da teoria à prática / Ubiratan D’Ambrosio. - Campinas, SP: Papirus, (Coleção Perspectivas em Educação Matemática).

Furlanetto, F. R. (2013) O movimento de mudança de sentido pessoal na formação inicial do professor. Tese (Doutorado em Educação) - Universidade de São Paulo, São Paulo.

Grando, R. C.(2004) O jogo e a matemática no contexto da sala de aula. (Coleção Pedagogia e Educação: 2004). São Paulo: Editora Paulus.

Moura, M. O. (1991) A construção do signo numérico em situação de ensino. São Paulo: USP.

Ramos, S. L. V. (2014)Jogos e brinquedos na escola: Orientação psicopedagógica. Editora Respel, p.192.

Ribeiro, F. D. (2009) Jogos e Modelagem na Educação Matemática. Saraiva. São Paulo.

Soares, E. S. (2010) Ensinar Matemática: desafios e possibilidades. Belo Horizonte: Dimensão.

Tahan, M. (1968) O homem que calculava. Rio de Janeiro: Record.

Recebido: $13 / 07 / 2019$

Aprovado:28/03/2020

Tangram - Revista de Educação Matemática, Dourados - MS - v.3 n.1, pp. 112-131 (2020) 